\title{
PUBLIC-PRIVATE COOPERATION MODELS FOR EFFICIENT ACCESS TO GEOSPATIAL CONTENT
}

\author{
${ }^{1}$ S.W. Musäus \\ ${ }^{1}$ Geospatial Content Solutions Division, Hexagon Geosystems, 08029 Barcelona, Spain - simon.musaeus@ hexagon.com
}

KEYWORDS: Basemaps, NMCA, Business Models, Geospatial Content, Public-Private-Partnership, Commoditization of Geodata

\begin{abstract}
:
Traditional public data procurement models for geospatial data sets as basemaps are not any longer alone the spatial reference for decision processes. A fast digitalizing society requires more flexibility and speed in the information streams. Public authorities have to deal with reducing budgets and higher demand, while the industry is searching for new business models. A smart and flexible design of public-private cooperation models increases the value for all stakeholders through (a) negotiated quality levels, (b) reduced unit prices, (c) stable income to all suppliers, (d) risk reduction to the authorities. The models allow for a high flexibility on product definition and orient themselves on the demands of the public and private markets alike.
\end{abstract}

\section{INTRODUCTION}

\subsection{From Hatching to Streaming to $X$}

Less than one professional generation ago, GPS was not relevant for civilian use, the internet was accessed through $26 \mathrm{kbps}$ Modems, and aerial photogrammetry required a film roll. While public institutions and academy were still adjusting to understanding, operating, and implementing the new technologies, with the fast-developing internet, new business models around geoinformation arose. Internet service providers, like Google, with their convenient streaming interfaces for borderless map data, and crowdsourced data sets, such as OpenStreetMap or OSM, filled very fast an apparent information void. On the supply side, the "age of drones" had not yet really started, but technology improvements connected to digitalization in remote sensing proved Moore's law right again when the capacity of sensors and processors exponentially improved. An opening of legislation in India and concomitant expansion of fast internet connections boosted the supply chain capacity for geodata processing globally. The demand side soared and all ahead, engineering firms, logistics companies, banks, and insurances rapidly demanded digital data to optimize internal processes. In the Engineering World digital interfaces often served as lesser but convenient substitutes of their analog parents, until it became clear that $\mathrm{CAD}$ and later Building Information Modelling(BIM) would not only open a new World of real 3D capabilities but also interface with other disciplines with ease, creating am ecosystem of spatial information technology and management. Adding the fourth dimension and wheels or wings and rotors to it, spatial optimization of traffic and even autonomous movement became possible. Individual users adopted and drove digitalization with the rise of smartphones and the availability of high-speed internet connections even faster. Geospatial information and its use are inseparably interwoven with our digital reality in every step - from entertaining games, such as PokemonGO to lifesaving applications such as COVID contact trackers. Between these two extremes, many standard applications are "running in the background" of everybody's life - building permits, restaurant suggestions, online advertisements, traffic control systems, real-estate valuation, and tax systems, to name a few.

Hardcopy and printed maps were traditionally and for lack of an alternative designed for human interpretation and decision making. In the beginning, digital maps served the same purpose, adding the convenience of easy transfer and actualization. The machines were only tools helping to generate a digital copy of a physical product, clearly "made by humans for humans." With the early navigation systems, the boundaries began to blur, when machines started consuming digital geoinformation and increasingly moved from suggestions for a decision to actual actions. Also, standards for Mapping had to be adjusted. "Snapping" one line to another was not only any longer an aesthetic element, but a necessary topological connection for the algorithms using the information. In the same way, visual elements such as colors, hill shades, and line styles, previously crucial for correct information transfer to the human observer, became less relevant compared to an infinite number of attributes that could connect to the elements. From the first steps of digitalization, computer programs have been used for quality checks of data, as it was captured by humans, and drawn by humans, just to make the final information digestible for machines. Today, in the age of artificial intelligence, machine learning enables computers to make sense of exabytes of (geo)data. A growing number of decisions are taken every second based on interpretation of geodata that - hopefully - reflects the actual state of the physical World which the decisions affect.

\subsection{What means "Fit-for-Purpose"?}

The idea of a World that requires a digital model of itself in realtime leads to an infinite number of purposes for the use of geoinformation. The definition of a purpose is even too broad for basemapping data, as it was traditionally designed to give most governmental planning processes a reasonable overview of the physical reality and the private user a sense of orientation.

With reference to ISO 25012, Yang et al. (2020) indicate that the quality of geodata(sets) can be measured in 


\section{- Completeness}

The degree to which subject data associated with an entity has values for all expected attributes and related entity instances in a specific context of use (ISO 25012) Currentness

The degree to which data has attributes that are of the right age in a specific context of use (ISO 25012)

Consistency

The degree to which data has attributes that are free from contradiction and are coherent with other data in a specific context of use. It can be either or both among data regarding one entity and across similar data for comparable entities. (ISO 25012)

\section{Accuracy}

The degree to which data has attributes that correctly represent the true value of the intended attribute of a concept or event in a specific context of use (ISO 25012)

The definition of the purpose for which the geodataset should be fit is anchored in the "specific context of use."

To translate the definition of the specific context of use for general purpose geodata for a state or a nation into quality requirements and standards is generally the responsibility of the National Mapping and Cadastre Agencies or short NMCAs.

Necessary quality standards and metrics of sensor measurements such as image resolution, image overlap, and point density are prescribed in the function of the expected quality of the final dataset.

An excellent example of standard generation, taking into account private sector involvement and cost-benefit assessment is of the USGS for finding the optimal point density and refresh cycle for a nationwide Airborne Lidar program, balancing the needs of twenty identified business uses (USGS, 2018.) In the case of the USGS model, even a previously non-existing, national Lidar standard with five quality levels was defined. The process shows that there exists a constant search for the balance between the cost of availability and the cost of a missed opportunity or a suboptimal solution due to a lack of appropriate geodata. Additionally, the creation of a Federal Lidar Standard supports the understanding that all elements of a unified spatial reference need to exist wall-to-wall for the geographical area in which the dataset is used for decision-making. Thus, data quality standards are necessary expressions of requirements for fitness-for-use.

The "Fit-for-Purpose" definition based on attributes of data appears to be incomplete if interfaces are taken out of the equation. The quality of access or accessibility determines the usability of the dataset. Parameters like available data formats, exchange protocols, visual interfaces, and - last but not least formal procedures determine value and fitness for the willing user as much or in some situations even more than the static datainherent parameters.

\subsection{Starting point NMCAs}

Most decision processes inside the government and especially at the interface with the public, such as taxation and infrastructure planning require a correct, coherent, and updated spatial reference. National Mapping and Cadastre Agencies, are, by law, custodians of the geospatial data infrastructure and the geospatial content used in governmental processes. It is widely understood that geospatial data certified by entitled NMCA becomes "authoritative" and, thus, is set to serve as a unified reference framework. The term "authoritative data" has been used differently across national entities, but the minimum characteristics are described as (a) trustworthy, (b) validated and certified by an authority, and (c) regulated (Plunkett, 2014). A unification has not yet been achieved and J. Crompvoets et al. (2019) recommended further steps for the creation of a descriptive framework for geodata comparable with the European Interoperability Framework and INSPIRE. While the beforementioned frameworks have reached maturity across major parts of Europe and beyond, the reality of available geodata, even for basemaps, shows large variations. Alone in Europe, there are hardly two neighboring countries that follow the same standards for this basic good in terms of completeness, currentness, consistency and accuracy, and accessibility.

Data dictionaries, update frequencies, spatial resolution, and, after the acquisition, time and form of accessibility vary widely. The most common data provider for basemap data is aerial surveying. A look at the aerial surveying programs of German authorities gives a good impression of the variety (AdV,2021) and the picture does not become less fragmented when taking a European perspective. The only thing, all basemaps, and data standards have in common, is that they end at the administrative boundaries for which the NMCA is responsible. The updated programs and standards for basemaps have developed over time and followed local purposes such as urban planning, traffic planning, and environmental policies, creating local optimization at best.

\subsection{The sources of (geo)data}

Most of the geospatial information for decision making and planning comes from remote sensing - Satellites and Aerial surveys. Satellite-borne camera systems allow a fast overview of large swaths of land at very high revisiting rates, but civil systems provide maximum resolutions of $30 \mathrm{~cm}$ per pixel and accuracies just below the meter. For machine-based decision-making and detailed planning, Airborne sensors create the largest percentage of high-resolution geoinformation and add a highly precise element of the 3D capability with the use of Airborne Lidar. Airborne imagery pixel resolutions reach into the centimeterlevel with accuracies below the decimetre and Lidar systems with measurement speeds of 6 million shots per second can create point densities of hundreds of points per $\mathrm{m} 2$. Recently, Mobile Mapping Systems, often combining imagery and lidar systems, are entering into a relevant role in the broader markets and close the "ground gap" of remote sensing. The combination of Imagery with Lidar in so-called hybrid systems, allows the capture of a wealth of geodata with high coherence and accuracy in short times, from air and ground. Transfer into highly accurate semantic 3D Meshes, that combine true orthophotos, DSMs, DTMs, and AI has come into reach in complete hybrid workflows, producing all the before in a single process.

\subsection{The reality of geodata}

National adaptation to technological progress, however, is not easy. To update their basemaps, some countries provide multiple national aerial coverages per year of up to $7,5 \mathrm{~cm}$ GSD (Ground sample distance: Size of one pixel on the ground,) and others consider $20 \mathrm{~cm}$ GSD every three years sufficient. The situation seems even more challenging when observing the third dimension - complete and current Lidar coverages are still a scarce good, and even in highly developed areas with densities lower than 8 points per $\mathrm{m}^{2}$ and updates every 3-10 (!) year far from being used to their potential. Countrywide oblique imagery or hybrid coverages, despite their high information content, are still rather exotic, and - again - limited to national boundaries. Any transborder planning process faces at least two different data standards and often considerable accuracy challenges. 
The reasons are mostly of structural and budgetary nature. To understand the structural constraints, a look into the history helps. Traditionally in the last 100 years, map making was the responsibility and prerogative of public civil and military institutions. In the beginning of aerial photogrammetry for basemapping, the nature of the data, often a military secret or an integrated part of governmental processes, and the necessary investment was outside of reach or interest of private investors. Thus, Mapping Agencies built their photogrammetric departments with airplanes, aerial cameras, photographic laboratories, map production, and expensive printing facilities. In the 1960s, private enterprises arose, but it took until the digitalization and diversification of data use that the roles started shifting.

In terms of basemap production, national authorities, being civil, military, or a mix of both, use operational models that reach from full autonomy to a simple curator role without any production capacity. We can distinguish various factors

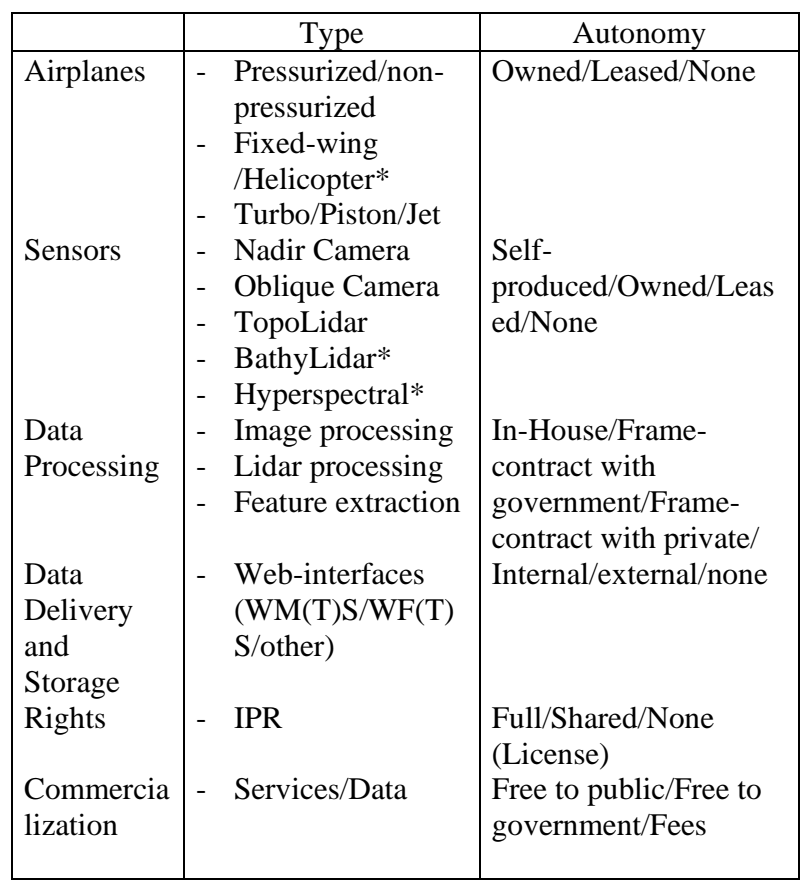

* Generally not relevant for basemaps

Table 1. NMCA Autonomy in Basemap production.

Today, the geodata required to satisfy the needs of a digitalizing and developing society exceeds by far the means of public institutions in terms of quantity, quality, and update frequency. The requirement of large internet providers for regional or even global mapping data gave birth to aerial and terrestrial content programs. With the acquisition of Keyhole, Google broke ground and created a mainly satellite-imagery-based early global digital twin. Others later followed suit, and by today many - mostly USbased - players own multi-continentwide high-resolution geodata sets, platforms, and services. While civil satellite imagery is increasing in resolution there are only limited resources for GSD $<50 \mathrm{~cm}$. Additionally, the acquisition date is hard to guarantee, it is usually difficult to capture cloud- and shadow-free, georeferentiation lacks the consistency of sameresolution aerial imagery (especially in 3D), it is relatively expensive over large areas, and licensing policies are often complex and one-sided.
Data capture and processing is increasingly becoming the responsibility of private enterprises, ready to invest in state-ofthe-art sensor and processing technology, able to build international supply chains, and willing to bear the economic risks with an eye on innovation, both technologically and business-model-related. A decreasing number of civilian public institutions retain the ability of own data capture and prefer the more convenient procurement of the necessary base data from the free markets. Today, alone in Europe exist more than 40 privately owned aerial surveying businesses (EAASI, 2021) compared to less than ten state-owned mapping organizations with full or partial aerial surveying capacity.

\subsection{Public-Private....Partnership?}

Public institutions, some being transformed into governmental companies with the call for co-funding of their budgets through commercialization of data and services, see themselves in a stretch between increasing demand, traditional structures and rules, and scarce resources. With the improvement of hardware and software for Map production and an increasing number of functioning private providers, there is a trend at NMCAs visible is to reduce the in-house capacity of data-capture and processing without harming the ability to provide the core services to administration and the public. Some reasons for a slow adaptation seem to be long-term, often lifetime public employment contracts for technical staff and, in some areas, the existence of a welcome opportunity for technical managers to change temporarily from a public employee salary to a better paying position in a stateowned production enterprise without losing the benefits. However, these seem to be exceptions.

Many NMCAs are already opting for a "curator role" and focus on the definition of data standards and quality guidelines, and later the enforcement of these during procurement contracts with the private industry. Mapping companies participate in competitive bidding processes for data acquisition or processing contracts and are later subject to strict deadlines, quality requirements, and other process instructions, facing potentially contractual penalties when these are not met. A focus on very detailed process descriptions in the technical documentation instead of only product-oriented requirements reflects the high procedural processing and capturing expertise still existing to varying degrees at the public counterpart. The overwhelming weight of the award decision lies in the final price, which has lead to steeply dropping unit prices for standard commodities, such as lidar point clouds and orthophotos.

Technical documentation in tenders often limits, in addition to quality requirements of the final product, the operational parameters such as flight level, image overlap, sensor field of view, and other sensor-related parameters. Thus, Aerial surveying companies have only a few options left to reduce costs. Acquisition of more powerful sensors is costly with prices of around one million Euros, and, like the use of better airplanes, usually only creates a commercial advantage that is eliminated by the dropping product prices. The cost of outsourcing laborintensive processes to third parties in India or elsewhere does not represent a competitive advantage any longer as it is open to everybody and hourly rates have reached hardly sustainable levels. So, how is a surveying business able to keep up with dropping prices?

The average aerial survey company is a small or medium-sized business (SMB) with less than 50 employees and 2-3 capital sensors. In Europe, sensors need to be operated commercially between 200 and 300 hours/year to pay for their amortization only, and standard fixed-wing, propeller-driven surveying aircraft follow similar patterns. Staff and facility costs increase over time, and the cost of capital has been stable over some years 
now, starting to rise again. Investment in processing technology is usually only compensating for price drops, and investment in potentially differentiating proprietary processes is complex, as it is expensive talent is hardly willing to work at normal salaries in a niche industry. Profit margins are already in the single-digit figures and dropping so that a break-even point becomes predictable. As air traffic restrictions and weather patterns are outside control, companies are choosing one or a mix of the following actions

a. Increasing the orderbook and balance the priorities in a geographic area during execution

b. Expand the customer base to private markets (individual customers or content programs)

c. Increase the number of yearly operating hours for equipment and FTE by competing for contracts in climate zones with extended or opposite weather patterns (e.g. Europe - West Africa, North-South America)

d. Expand the business model (data sales, non-mapping surveys, air transport)

In Europe, authorities decide increasingly to adopt open-data policies (European Commission, 2020b). Open data policies are mainly driven by two factors: Value-generation in the market by eliminating a barrier to data access, expecting an ROI of 5:1 in the economy, and transparency, by giving access to a public good paid by taxpayers money. All the above need to be done, strictly abiding by the laws for the protection of privacy (e.g. GDPR.) Thus, NMCAs have become even more restricted in the options for commercialization of the data and tend to reduce the internal and external cost of procurement of data and services even further.

In conclusion, as geoinformation products are a valuable commodity, the general challenge has become to balancing the NMCA's request for high-quality data at low cost in time, the Aerial Surveying Industries' need for a sustainable business while maintaining the ability to invest in innovation and talent, and the digital societies' increasing demand for coherent, accessible, and borderless geoinformation.

\section{NEED FOR NEW MODELS}

\subsection{Existing procurement models for aerial survey data}

Geospatial information, if obtained from the free markets, is commonly procured in a data-for-pay or service-for-pay model. While there are contractual differences between both with regards to warranties, guarantees, and other liabilities, the fundamental understanding is that a public entity obtains ownership of a dataset according to elaborated specifications.

The cooperation with the data producer is merely transactional and closes with the handover and acceptance of the dataset by the buyer, potentially followed by a longer period in which the producer is obliged to correct defects.

In a data-for-pay model, the buyer would focus on the description of the characteristics of a final product, such as accuracy, period and currentness of data acquisition, and delivery formats. For imagery, a definition of maximum cloud cover, radiometric parameters, solar angle, maximum building lean, and minimum image size might be added, while for Lidar coverages a specific point density and distribution and full-wave-form requirements are requested.
If a service-for-pay model is applied to obtain principally a dataset, the restrictions become more accentuated. On top of the specifications for the end-product, the buyer narrows down even the operational parameters of the acquisition company. Now the buyer asks additionally for a minimum number of ground control points, specific flight levels, acquisition flight directions, and even parameters that are today questioned in their usefulness, such as a specific image overlap and a maximum diameter of lidar beam foot-prints. In some cases, the buyer asks for the exclusivity of the use of the aerial platform, similar to a wet-lease contract, and restricts such the parallel use of other measurement equipment.

The complexity of both approaches is the restriction of the contractor to deliver data or data plus service in an exclusive, transactional process under an increasing cost pressure which leads to the NMCAs facing problems to obtain high-quality datasets for the budgets and in the time available.

At the same time, the demand for quality geodata is on the rise, and the datasets generated by public procurement are neither the only spatial reference used any longer, nor are they sufficiently homogenous and current for the new use-cases such as autonomous transport, 5G telecommunication, and disaster preparedness.

\subsection{Cooperation models}

Geospatial datasets have, without doubt, become part of the critical infrastructure of the digital society. Any planning process that affects or is affected by the spatial order of the moment, leading to prioritization of funding and legislation, requires current, accurate, and coherent data. It is also safe to assume that the traditional "buy-to-own" models, be it through service or product procurement, have become too static and restrictive for a growing number of use-cases. These use-cases often exist outside the direct influence of the public authorities, such as $5 \mathrm{G}$ network planning and require data to a degree of consistency which existing "authoritative" data does not offer. In other places, in the developing World, basic requirements, such as countrywide current maps for Land administration projects are not updated in time due to lack of funding and a limited ability to coordinate the requirements of governmental entities for a spatial reference. In the first case, funds are wasted, as valuable datasets are generated outside the public and not adopted, and in the second case, opportunities are lost as processes requiring the data cannot be finished.

In both cases, it falls back to the responsibility of the government to serve the best interest of the broader public, either by carefully managing public funds or put the right data at the disposal of decision-makers in time.

In all cases, it is enlightening to have a look at the cooperation models developed in the infrastructure industry. When faced with the need for satisfying a rapidly rising demand for new infrastructure, governments understood that cooperation with the private industry helped in potentially various ways, depending on the nature of the agreement:

- $\quad$ Focus on the total cost (production plus maintenance) incentivizes optimization

- Rebalancing responsibilities draw on the managing ability of the private industry

- $\quad$ Access funding from the private markets

Several cooperation models are worthwhile to consider in the geospatial industry. 


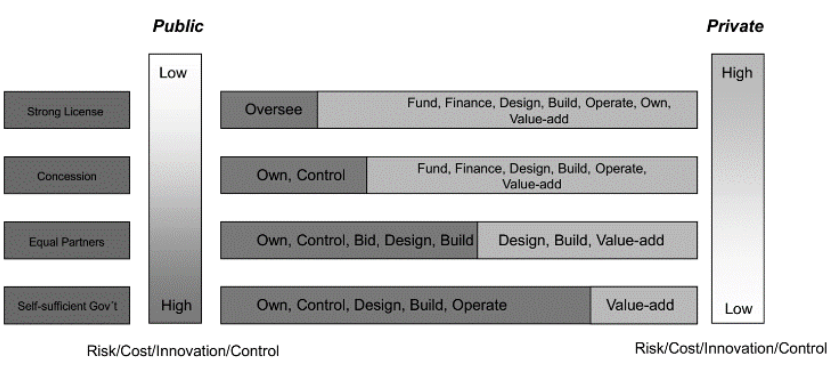

Figure 1 Public-Private Cooperation Models.

The target is to maximize the value for the users, the owners, and the contractors at once while balancing the responsibilities and risk.

Generally, and with a side-look to the construction industry, four levels can be defined (Fig. 1)

1. Self-sufficient government

In this level, the full cost and risk for building and operating the data and access infrastructure remains with the government. The private industry has an opportunity to use the data after purchase or obtaining it from the public domain.

2. Transaction

Governmental entities invite consultancy for the definition of the product and retain a part of the production or access technology in-house while purchasing other elements from the private market.

3. Concession

Public entities retain a reasonable amount of control on the data and access through ownership rights. The private partner produces the data and operates the access, being either paid by the government or the users.

4. Co-Creation and License

The private entity fully produces, operates, and owns the data and infrastructure. The government may have some influence in the design and acquires licenses of different levels of rights. (Example: Satellite Data)

The models depict in an increasing order more responsibility for the industry with concomitant risk reduction and cost saving for the public. Today's NMCA's operation and commercial models can be found all along this scale, but still with the majority following a "Self-sufficient government" or "Transaction" approach. Some forward-thinking authorities in Europe are implementing Concession models by retaining the ownership rights but leaving the commercialization to the private players. The most advanced is the Licensing model. It is mostly applied to satellite data and increasingly with content programs, such as the Hexagon Content Program. (Hexagon, 2021) as the implementation requires a considerable upfront financing in infrastructure and acquisition.

Major players of the geospatial industry are today organizing their partner networks for aerial photogrammetric and Lidar surveys, and increasingly mobile mapping. Sizeable, coordinated airfleets with state-of-the art sensors cover large swaths of the Earth's surface and collect imagery or Lidar to standardized specifications. Internationally connected data-centers refine the raw-data to products from simple true orthophotos to 3D Meshes, GIS-Layers, and 3D Models. The turnaround times between data acquisition and delivery of the final product are due to the applied high-performing infrastructure and uniformity of data generally a fraction of the traditional delivery times, and so are the unit prices for licenses when compared to bespoke projects over small areas and a variety of specifications.

After processing and final quality check, the geodata are uploaded to web services to become available globally to the interested licensee. Data access is arranged either directly with the owning company or through resellers through standardized interfaces and protocols.

Content programs offer a variety of benefits for all players in the market

1. To the Licensee

Cost reduction (full lifecycle)

Fast and risk-free availability

Predictable and consistent quality

Convenient Access

2. To the Private Owner

Cost reduction through bulk-production

Additional income through multiple licensing

3. To the Team partners

Continuous billability of capital assets (sensors, airplanes)

- Additional income through revenue share

4. To the Resellers

Additional revenue streams

Novel product

5. To the Public and the final user

Consistent data over large areas - usually crossing national and state boundaries

- Convenient access

- Predictable refresh cycles

These cooperation are today facilitating a co-creation concept for geospatial content programs, which give public authorities great freedom of defining the specifications for their territory. On the other hand, the industry commercializes the data broadly in the marketplace which allows for stabilization of income and prices for geodata.

One concern of NMCAs is that areas that show a low demand for the data on the free markets could be neglected by the program and face reduced refresh cycles. While these areas might not show much change in reality, and low demand could be a regulator, NMCAs could take advantage in the License negotiation and steer the priorities of the acquisition by higher contribution in low demand areas, balanced by lower unit prices in the high demand areas (Fig.2.)

Some NMCAs are voicing concerns about the application of Open Data policies. However, also here, the benefits of exceptions, following thoughts about the B2G data sharing of the European Commission, might outweigh the concerns (European Commission, 2020a.)

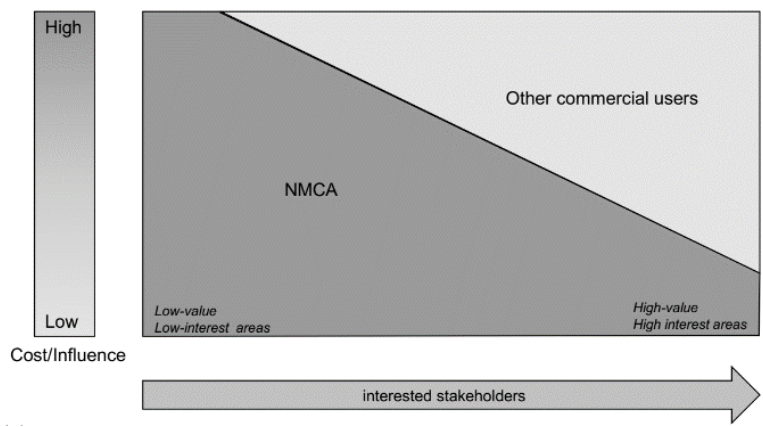

Figure 2. NMCA leverage on the content program.

The PPP KnowledgeLab defines a public-private partnership as 
A long-term contract between a private party and a government entity, for providing a public asset or service, in which the private party bears significant risk and management responsibility and remuneration is linked to performance. (PPPKnowledgelab, 2021)

Licensing or Concession agreements render the best results when they are designed with a long-term vision, and between players who understand the relationship as an actual partnership. While the private side bears the larger part of initial investment and overall management responsibility, good governance and clear financial management are necessary.

The freedom to decide on "government-pays" or "user-pays" concepts allows the private player to serve a much broader market. Focus on the lifetime cost of the relationship can also benefit society and the environment by investing in modern technology and talent.

\section{CONCLUSION AND OUTLOOK}

\subsection{Conclusion}

A smart and flexible design of Public-Private Cooperation models increases the value for all stakeholders through (a) negotiated quality levels, (b) reduced unit prices, (c) stable income to all suppliers, (d) risk reduction to the authorities and the private. Some models allow for high flexibility on product definition and orient themselves on the demands of the public and private markets alike. Models might even be mixed and matched to pay respect to the legislative realities.

NMCAs can focus on their primary task as guardians of standards and guide the supply to underserved zones by leveraging their influence in the negotiation of content programs.

\subsection{Outlook}

Many governments, mainly in North America, but also increasingly in Europe are moving in the geospatial data provision and infrastructure towards stronger private involvement. The role of NMCAs as curators of the data towards the public will be more focused on designing their data procurement models to reap the financial benefits, while at the same time abide by privacy protection and transparency legislations of digitalizing societies.

\section{REFERENCES}

AdV, (2021). Bundesweite Bildflugübersicht 2021.

http://www.adv-online.de/AdV-

Produkte/Geotopographie/Luftbildprodukte/

Crompvoets, J. et al. (2019). Authoritative Data in a European Context. EuroSDR \& KU Leuven.

https://eurogeographics.org/wp-content/uploads/2020/02 /Pub72 AuthoritativeData.pdf

European Commission (2020a). Analytical Report 12: Businessto-Government Data Sharing. Luxembourg: Publications Office of the European Union, 2020 (C) European Union, 2020. doi: $10.2830 / 078126$
European Commission (2020b). Open Data. https://digitalstrategy.ec.europa.eu/en/policies/open-data-

0\#: :text=The\%20European\%20Commission's\%20policies\%20 focus,reuse $\% 20 \mathrm{of} \% 20$ public $\% 20$ sector $\% 20$ information.\&text= The $\% 20 \mathrm{EU} \% 20$ open $\% 20 \mathrm{data} \% 20$ market,the $\% 20$ overall\%20E U\%20data\%20economy.

Hexagon, (2021). HxGN Content Program. https://hxgncontent.com/

Plunkett, G. (2014). What does the term "Authoritative Data" Really mean? Environmental Systems Research Institute Canada.

PPPKnowledgeLab, (26.04.2021). Introduction. https://pppknowledgelab.org/guide/sections/1-introduction

UN-GGIM (2020). Future Trends in geospatial information management: the five to ten year vision. 3rd ed. August 2020.

USGS, (2018). 3D Elevation Program.

https://www.usgs.gov/core-science-systems/ngp/3dep

Yang, J.J., Hvidsten A.K., Borrebaek, M. (2020). Data Quality in an e-Government Perspective. Workshop Report "3 $\mathrm{rd}$ International Workshop on Spatial Data Quality (SDQ 2020).” January 28th - 29th 2020 - Valletta, Malta 